\title{
Acute organ failure following the loss of anti-apoptotic cellular FLICE-inhibitory protein involves activation of innate immune receptors
}

\author{
N Gehrke ${ }^{1,5}$, D Garcia-Bardon ${ }^{1,5}$, A Mann ${ }^{1}$, A Schad ${ }^{2}$, Y Alt ${ }^{1}$, MA Wörns ${ }^{1}$, MF Sprinzl ${ }^{1}$, T Zimmermann ${ }^{1}$, J Menke ${ }^{1}$, AJ Engstler ${ }^{3}$, \\ I Bergheim ${ }^{3}$, Y-W He${ }^{4}$, PR Galle ${ }^{1}$, M Schuchmann ${ }^{1,6}$ and JM Schattenberg ${ }^{\star, 16}$
}

Apoptosis signaling is involved in both physiological tissue homeostasis and acute and chronic diseases. The role of regulatory apoptosis signaling molecules and their organ-specific functions are less defined. Therefore, we investigated the loss of the antiapoptotic cellular FLICE-inhibitory protein (cFLIP) and the mechanisms of the resulting lethal organ failure in vivo using inducible knockout mice. These were generated by crossing floxed cFLIP mice to a tamoxifen inducible Rosa26-creERT2 mouse strain. Death following global loss of cFLIP resulted from liver failure, accumulation of M1-polarized macrophages and accompanying hepatic cell death and inflammation. Apoptosis was also prominent in immune cells, the kidney and intestinal epithelial cells (IECs) but not in cardiomyocytes. Cellular injury led to the release of damage-associated molecular patterns (DAMPs) and the induction of innate immune receptors including toll-like receptors (TLRs) 4 and 9, and stimulator of interferon genes (STING). Transplantation of bone marrow with intact cFLIP or depletion of macrophages prevented the phenotype of acute liver failure. Interestingly, compound deletion of cFLIP in bone marrow-derived cells and hepatocytes did not promote organ failure. Thus, cFLIP exerts a critical role in tissue homeostasis by preventing the activation of monocytic cells and innate immunity, which causes cell death and inflammation in susceptible tissues. These results encourage the development of organ-specific anti-apoptotic and antiinflammatory therapies in acute organ failure.

Cell Death and Differentiation (2015) 22, 826-837; doi:10.1038/cdd.2014.178; published online 24 October 2014

The mortality of acute organ failure is high and the underlying pathophysiological mechanisms are poorly understood. Cellular injury from controlled (apoptosis and necroptosis) or uncontrolled (necrosis) cell death and metabolic, regulatory modes of tissue turnover (autophagy) contribute to the regulation of tissue homeostasis. Even minor alterations in the finely tuned balance of proliferation and cell death can lead to severe organ dysfunction or cancer. ${ }^{1}$ In hepatocytes, apoptosis can be initiated through an extrinsic or intrinsic signaling pathway. Activation of the extrinsic signaling cascade involves cell surface bound receptors among which the tumor necrosis factor (TNF)-receptor superfamily is the most prominent. ${ }^{2}$ Receptor-mediated apoptosis involves formation of an intracellular death-inducing signaling complex (DISC), which includes procaspase 8 and cellular FLICEinhibitory protein (cFLIP) among others. ${ }^{2}$ cFLIP is a caspase 8 homolog and exerts anti-apoptotic function by blocking caspase 8 activation. Loss of CFLIP has been shown to result in embryonic lethality from increased apoptosis of cardiomyocytes. ${ }^{3}$ cFLIP is critically involved in apoptosisand stress-signaling pathways in $\mathrm{IECs},{ }^{4}$ hepatocytes, ${ }^{5-7}$ lymphocytes ${ }^{8}$ and myeloid lineage-derived cells. ${ }^{9}$ Recently, Piao et al. ${ }^{10}$ showed that deletion of cFLIP using different transgenic mouse strains impaired hepatocyte and IEC survival by inducing cell death dependent on TNF, Fas ligand and TNF-related apoptosis-inducing ligand (TRAIL). Additionally, a Mx1-Cre line was used to assess the role of cFLIP in global cellular homeostasis and in these mice a phenotype with fatal hepatitis was observed. However, these studies did not exclude that interferon (IFN)-dependent signals triggered by poly I:C could promote cellular injury through, for example, TLR3 and melanoma differentiation-associated protein 5 (MDA-5). Also, the underlying pathomechanisms of this phenotype remained unresolved.

To investigate the mechanisms of cFLIP-induced organ failure, we generated mice with conditional, ubiquitous deletion of CFLIP by crossing floxed CFLIP//f mice to a tamoxifen-inducible Rosa26-creERT2 mouse strain. Loss of cFLIP resulted in acute liver failure characterized hypoglycemia and hyperbilirubinemia, and was accompanied by depletion of intrahepatic leukocytes and the activation of inflammatory macrophages. All mice died within $96 \mathrm{~h}$.

\footnotetext{
${ }^{1}$ I. Department of Medicine, University Medical Center of the Johannes Gutenberg University, Mainz, Germany; ${ }^{2}$ Institute of Pathology, University Medical Center of the Johannes Gutenberg University, Mainz, Germany; ${ }^{3} \mathrm{SD}$ Model Systems of Molecular Nutrition, Friedrich-Schiller University, Jena, Germany and ${ }^{4}$ Department of Immunology, Duke University, Durham, NC, USA

*Corresponding author: JM Schattenberg, I. Department of Medicine, University Medical Center of the Johannes Gutenberg University, Langenbeckstraße 1, Building 601, 1st Floor, Room 1.124, Mainz 55131, Germany. Tel: +49 6131 176074; Fax: +49 6131 17477282; E-mail: schatten@ uni-mainz.de

${ }^{5}$ These authors contributed equally to this work.

${ }^{6}$ Last authorship is shared.

Abbreviations: BMC, bone marrow-derived cells; cFLIP, cellular FLICE-inhibitory protein; DAMP, damage-associated molecular pattern; JNK, cJun N-terminal kinase; LPS, lipopolysaccharides; MAPK, mitogen-activated protein kinase; STING, stimulator of interferon genes; TLR, toll-like receptor; TNF, tumor necrosis factor $\alpha$ Received 05.4.14; revised 13.9.14; accepted 16.9.14; Edited by D Vaux; published online 24.10.14
} 
Interestingly, this phenotype was not explained by the loss of cFLIP in hepatocytes or hematopoietic cells alone, indicating an organ-spanning crosstalk or the involvement of further compartments. Furthermore, we show that DAMPs, including cell-free double-stranded (ds)DNA, released during cell death induce upregulation and activation of dsDNA-sensing endosomal and cytosolic signaling pathways, namely TLR9 and STING, which contribute to an overwhelming inflammatory immune response and cell death. This phenotype was prevented by replenishment of cFLIP in bone marrowderived cells (BMC) or depletion of macrophages.

\section{Results}

To investigate the physiological role of cFLIP in vivo, we generated inducible cFLIP-deficient mice (FLIP ${ }^{\mathrm{f} / \mathrm{f}}$-creERT2) that exhibit a tamoxifen-inducible cre-recombinase. ${ }^{8,11}$ The efficiency of cFLIP deletion was confirmed in hepatic, spleen and intestinal tissue at $48 \mathrm{~h}$ by immunohistochemistry (Figure 1a), immunoblotting (Figure 1b) and qRT-PCR (Figure 1c), indicating reduction of cFLIP protein expression by $40 \%$. Reduction of cFLIP protein led to acute liver failure with elevated serum alanine-aminotransferase (ALT) (Figure 1d), hypoglycemia (Figure 1e) and elevated lactate dehydrogenase (LDH) (Figure 1f). In addition, loss of liver function was characterized by increased serum bilirubin levels and a prolonged prothrombin time (Figure 1f). All mice died within $96 \mathrm{~h}$ (Figure 1g).

Hematoxylin and eosin (H\&E) stainings showed increased amounts of apoptosis and immune cell infiltrates in liver, spleen, kidney and intestinal tissue of FLIP $^{\mathrm{f} / \mathrm{f}}$-creERT2 mice at $48 \mathrm{~h}$ following tamoxifen treatment (Figure 2a). In contrast, heart or brain showed only marginal alterations in apoptotic rates (data not shown). Also, terminal dUTP nick-end labeling (TUNEL) staining and immunohistochemistry for cleaved caspases 8, 9 and 3 revealed apoptosis in hepatic, spleen and intestinal tissue (Figures $2 b$ and e). In line with the role of caspases in this type of injury, pretreatment with the pancaspase inhibitor zVAD ameliorated liver injury, normalized blood glucose levels (Figures $2 \mathrm{c}$ and $\mathrm{d}$ ) and blocked caspase activation (Figure $2 \mathrm{e}$ ). This implies that caspasedependent apoptotic processes are the predominant type of cell death in response to loss of cFLIP.

Stress kinases and pro-inflammatory cytokines mediate acute liver failure. To assess the involved mechanisms, stress kinase signaling pathways were examined. The mitogen-activated protein kinase (MAPK) JNK has been shown to regulate apoptotic liver injury and hepatic fibrosis. ${ }^{12,13}$ Following loss of cFLIP, increased phosphorylation of the p46 and p54 JNK isoforms and activation of the downstream transcription factor cJun (Figure 2f) were detected. Analysis of serum cytokines/chemokines showed a significant increase in IL-6, IFN- $\gamma$, TNF and the macrophage-attractant chemokine CCL2 (MCP-1) in FLIP ${ }^{\mathrm{f} / \mathrm{f}}$ creERT2 mice. Cytokine/chemokine levels reached a maximum at $36 \mathrm{~h}$ and declined thereafter (Figure 3a). Their potential source are resident immune cells in the liver or extrahepatic immunocompetent cells. Thus, their expression levels in liver and spleen were examined. Expression of IL-6,
TNF, CCL2, IL-1 $\beta$, IFN- $\alpha$ and $-\beta$ was markedly upregulated in whole liver lysates of FLIP $^{\mathrm{f} / \mathrm{f}}$-creERT2 mice at $48 \mathrm{~h}$ post tamoxifen (Figure $3 \mathrm{~b}$ ) indicative of acute inflammation. In contrast, an enhanced expression of IFN- $\gamma$ but not TNF, IL-6 or CCL2 was detected in CD11 $\mathrm{b}^{+}$splenocytes derived from tamoxifen-treated FLIP $^{\mathrm{f} / \mathrm{f}}$-creERT2 mice (Figure 3c), indicating that the source of IFN- $\gamma$ was extrahepatic $C D 11 b^{+}$ immune cells. These data underline the activation of immunocompetent cells in response to loss of cFLIP.

Intrahepatic, immunocompetent cell populations are activated following loss of cFLIP. To assess the contribution of intrahepatic leukocyte populations, FACS analyses were performed. At $48 \mathrm{~h}$, a significant loss of $C D 45^{+}$ immunocompetent cells in the liver of FLIP $P^{\mathrm{f} / \mathrm{f}}$-creERT2 mice was observed (Figure 4a). Quantification of different leukocyte subsets (Figure $4 b$ ) revealed a significant reduction in relative numbers of $\mathrm{T}$ and $\mathrm{B}$ lymphocytes but a significant relative increase in macrophages in the liver following the deletion of cFLIP. The relative numbers of NK cells were slightly higher. In contrast, the absolute number of macrophages and NK cells seemed to increase over the first $36 \mathrm{~h}$ after deletion of cFLIP _ likely related to an enhanced recruitment of these immune cells - and then decreased in parallel to the number of lymphocytes (Figure 4c, data not shown). Also, immunohistochemistry and qRT-PCR revealed the decrease in intrahepatic F4/80 cells and F4/80 gene expression at $48 \mathrm{~h}$ in $\mathrm{FLIP}^{\mathrm{f} / \mathrm{f}}$ creERT2 mice (Supplementary Figure $1 \mathrm{~A}$ and $\mathrm{B}$ ).

To determine the sensitivity of lymphocytes $\left(C D 11 b^{-}\right)$and monocytes/macrophages $\left(\mathrm{CD} 11 \mathrm{~b}^{+}\right)$to undergo apoptosis following the loss of cFLIP, CD11 $\mathrm{b}^{-}$and CD11 $\mathrm{b}^{+}$splenocytes were examined ex vivo. The viability of CD11 $b^{-}$and CD11 $b^{+}$ cells decreased at $48 \mathrm{~h}$ following deletion of cFLIP in vitro. Interestingly, survival of $\mathrm{CD}_{11 b^{-}}$cells derived from FLIP $^{\mathrm{f} / \mathrm{f}}$ creERT2 mice was significantly lower as compared with $\mathrm{CD}_{11 \mathrm{~b}^{+}}$cell populations (62 versus 83\%; Figure 4d). Together, these findings suggest that monocytes/macrophages are less sensitive to cell death following deletion of cFLIP than CD11b- lymphocytes and persistence of these cells in the liver could be related to the inflammatory phenotype observed. In addition, FACS analysis of peripheral blood also revealed a strong reduction of lymphocytes in FLIP ${ }^{\mathrm{f} / \mathrm{f}}$ creERT2 mice already at $36 \mathrm{~h}$, while the number of macrophages and NK cells was not altered (data not shown). Surprisingly, the relative composition of leukocyte subsets in the spleen was hardly affected (data not shown). These results point toward a differential sensitivity of lymphocytes and macrophages to undergo cell death following deletion of cFLIP also depending on the harboring organ.

Macrophages are responsible for inflammation and liver injury following loss of cFLIP. To further address the role of intrahepatic macrophages in acute liver failure, polarization was analyzed using antibodies directed against classically activated M1 macrophages (CD80, CD86 and I-A $)$ or alternatively activated M2 macrophages (CD206). Compared with wild-type controls, macrophages in the liver of FLIP $^{\mathrm{f} / \mathrm{f}}$ creERT2 mice showed higher expression for CD80 and CD86 and lower CD206 expression following tamoxifen injection (Figure $4 \mathrm{e}$ ), indicating a predominance of an inflammatory, 
a
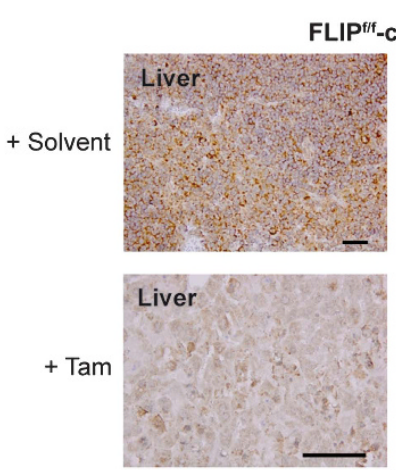

Wild type
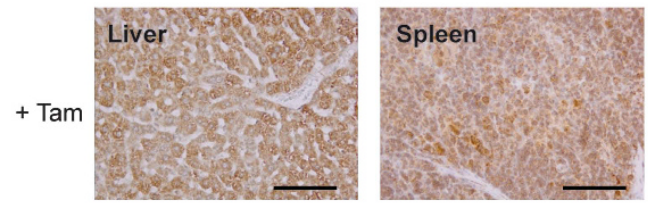
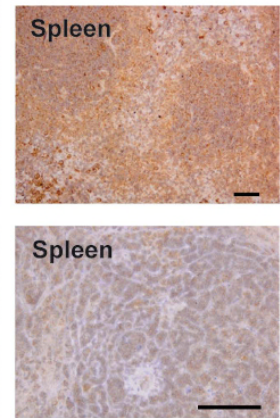
. b

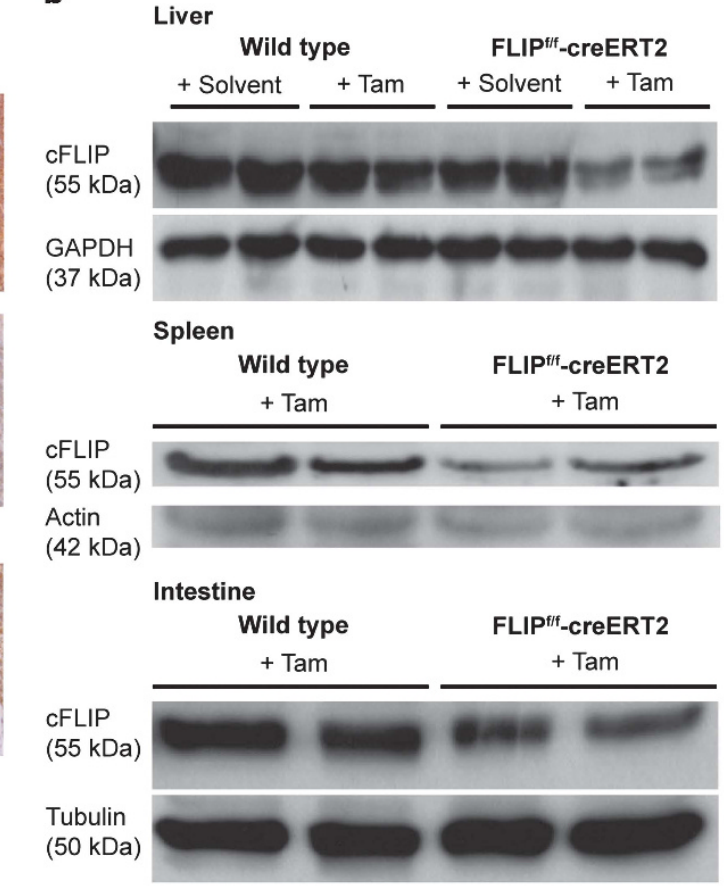

c
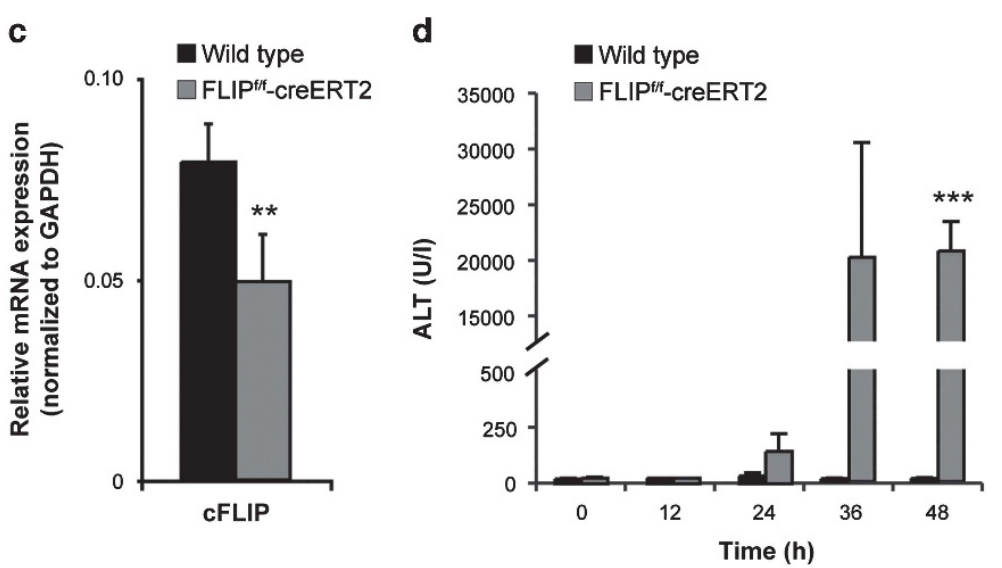

f
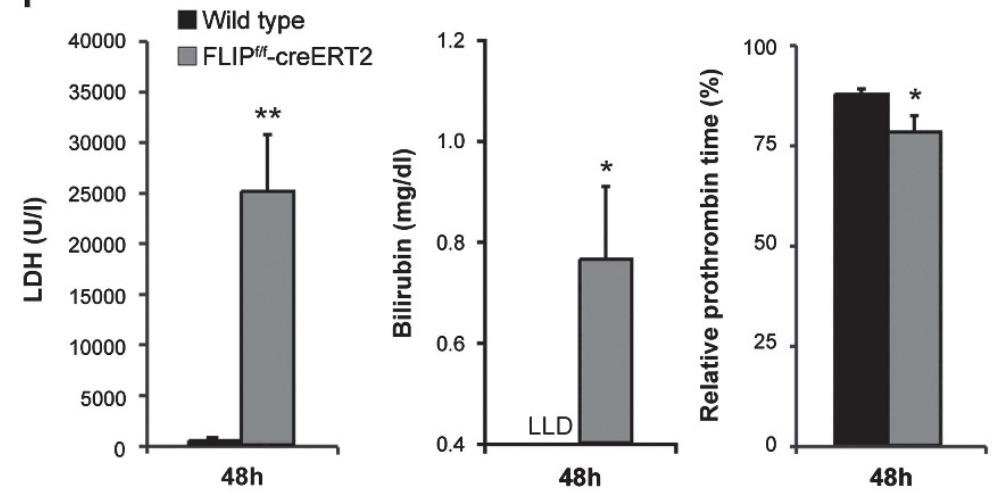

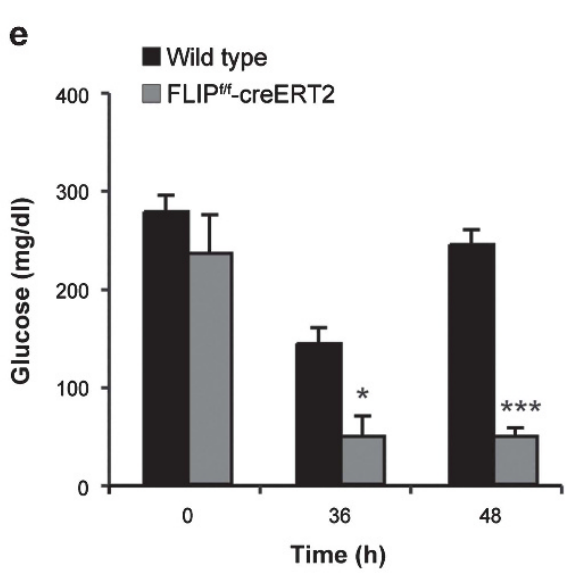

g

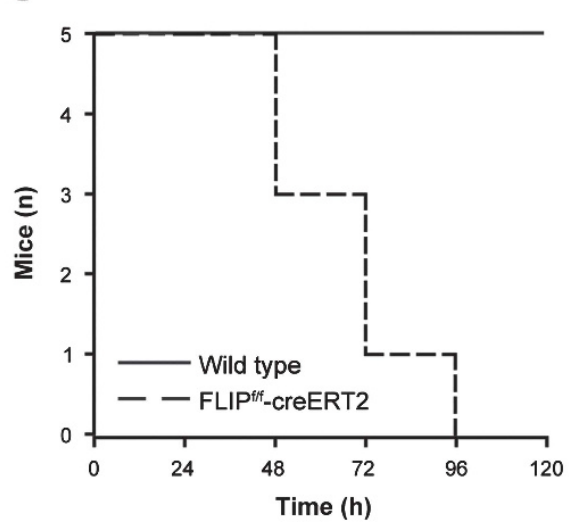

Figure 1 Deletion of cFLIP in mice leads to acute liver failure and death. Expression of cFLIP was determined by (a) immunohistochemistry (scale bar: $2000 \mu \mathrm{m}$ ), (b) immunoblotting and (c) qRT-PCR in liver, spleen and intestine of wt and FLIP/f-creERT2 mice following injection with tamoxifen or solvent at $48 \mathrm{~h}$. (d) Serum ALT, (e) blood glucose, (f) serum LDH, bilirubin (LLD = lower limit of detection), relative prothrombin time and ( $g$ ) overall survival were determined at the indicated time points following treatment with tamoxifen. Data represent mean \pm S.E.M. (c-g: $n=5-9$ mice/group), $P$-values for wt versus FLIP ${ }^{\mathrm{f} / f}$-creERT2: ${ }^{*} P<0.05,{ }^{* \star} P<0.01,{ }^{* \star *} P<0.001$ 
a

Liver
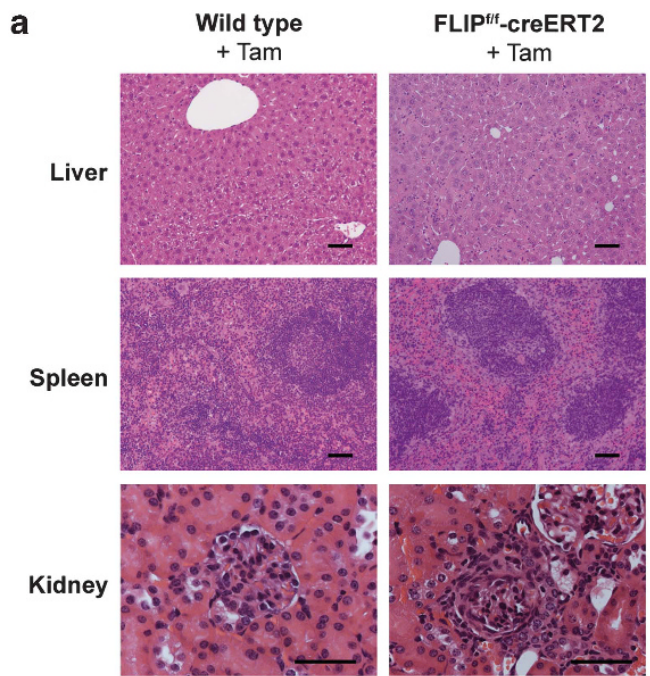

Intestine
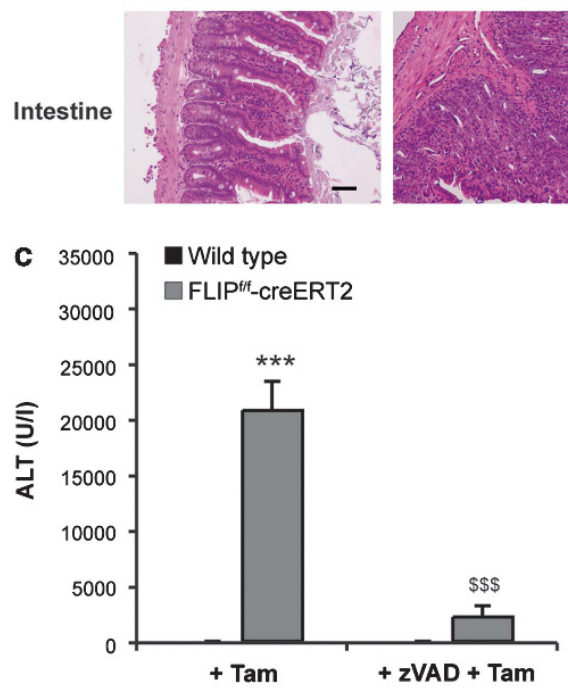

e
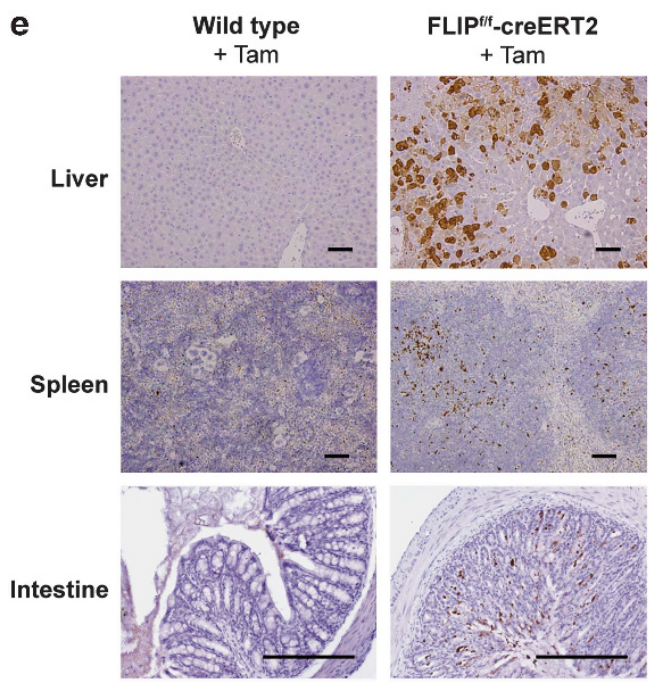

Figure 2 Liver injury in FLIP/f-creERT2 mice is caspase dependent and involves JNK activation. (a) Histological sections stained with hematoxylin and eosin (scale bar: $2000 \mu \mathrm{m}$ ), (b) TUNEL (scale bar: $2000 \mu \mathrm{m}$ ) and immunohistochemistry for activated caspases (scale bar: $2000 \mu \mathrm{m}$ ) in liver from wt and FLIP ${ }^{\mathrm{ff}}$-creERT2 mice are shown at $48 \mathrm{~h}$ post tamoxifen. (c) ALT, (d) blood glucose and (e) caspase 3 activation in liver, spleen and intestine (scale bar: $2000 \mu \mathrm{m}$ ) were assessed following pretreatment with zVAD or solvent (DMSO) for $1 \mathrm{~h}$. (f) Activation of JNK and c-Jun was determined by immunoblotting in whole liver lysates at $48 \mathrm{~h}$. Data represent mean \pm S.E.M. (c and d: $n \geq 7$ mice/ group), $P$-values for wt versus FLIP ${ }^{f / f}$-creERT2: ${ }^{\star} P<0.05$, ${ }^{\star *} P<0.01,{ }^{\star \star *} P<0.001$ and for FLIP/f-creERT2 mice $\pm \mathrm{zVAD}:{ }^{\$} P<0.05,{ }^{\$ \$} P<0.01,{ }^{\$ \$ \$} P<0.001$ b
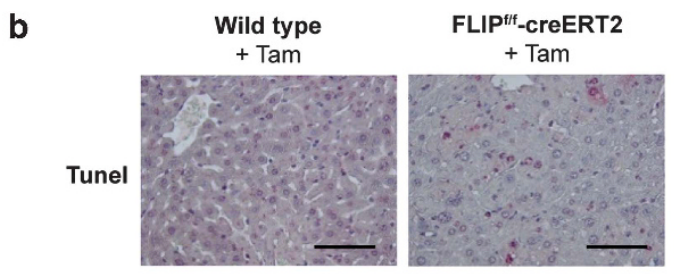

Caspase 8

Caspase 9

Caspase 3
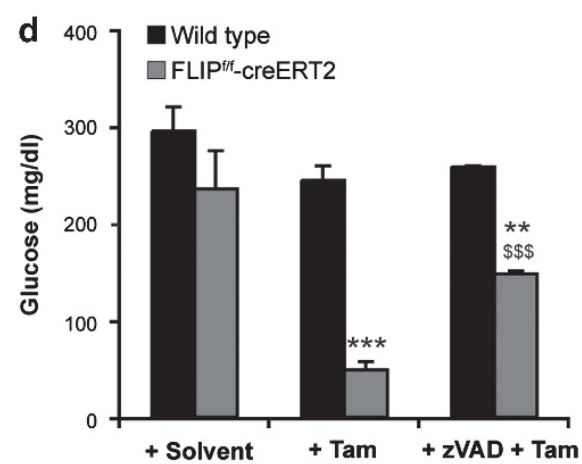

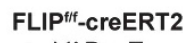

+ zVAD + Tam
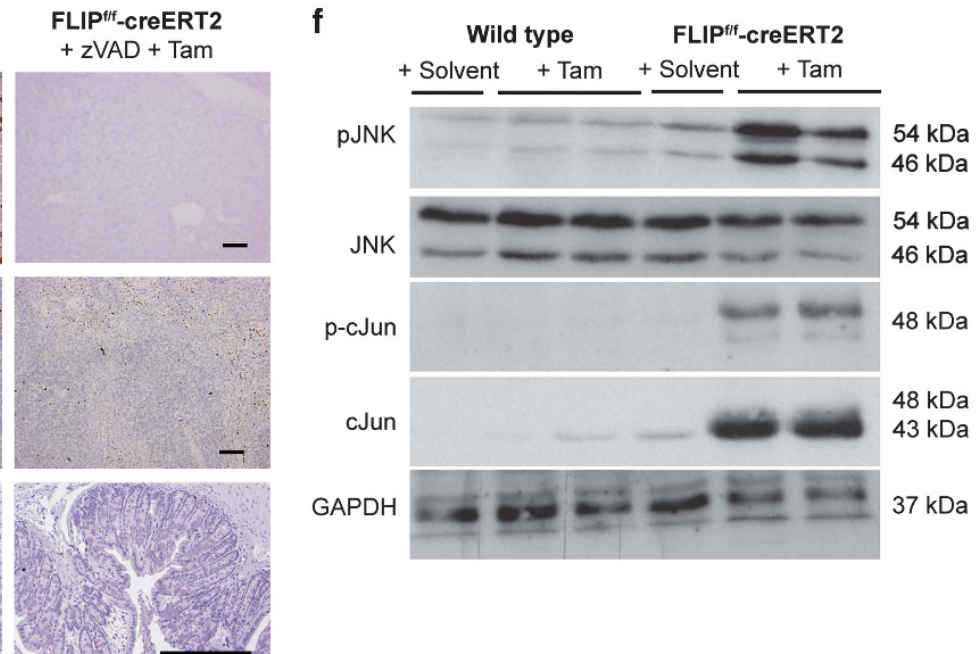
a

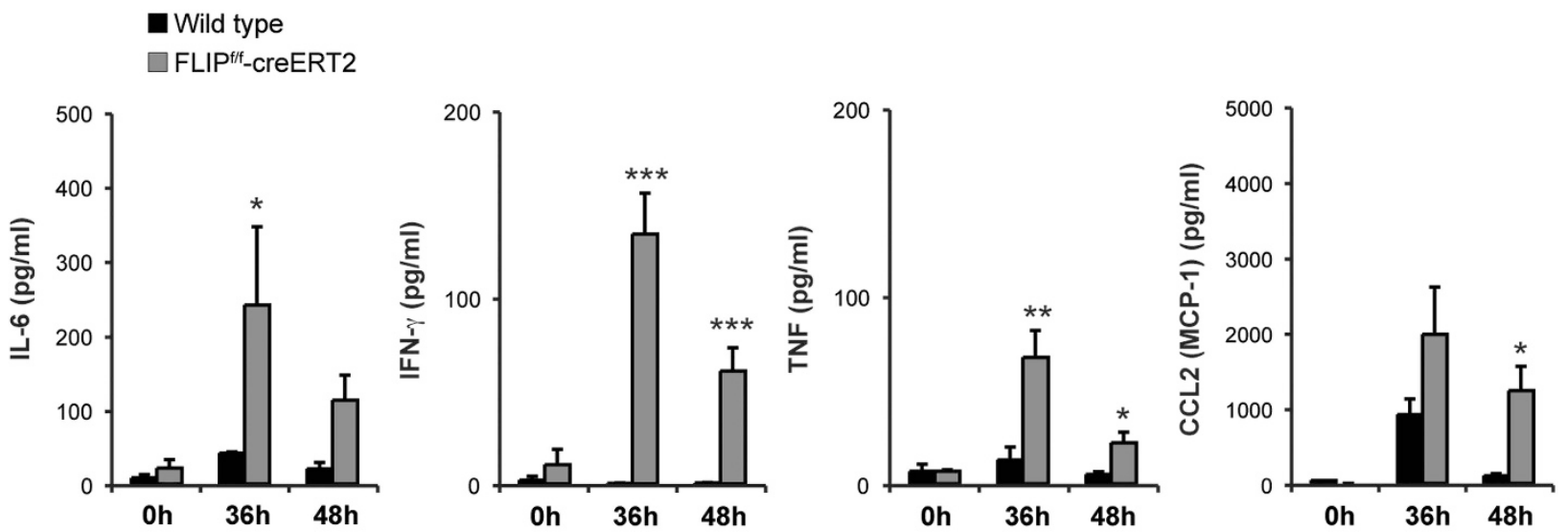

b

Wild type

FLIPff-creERT2
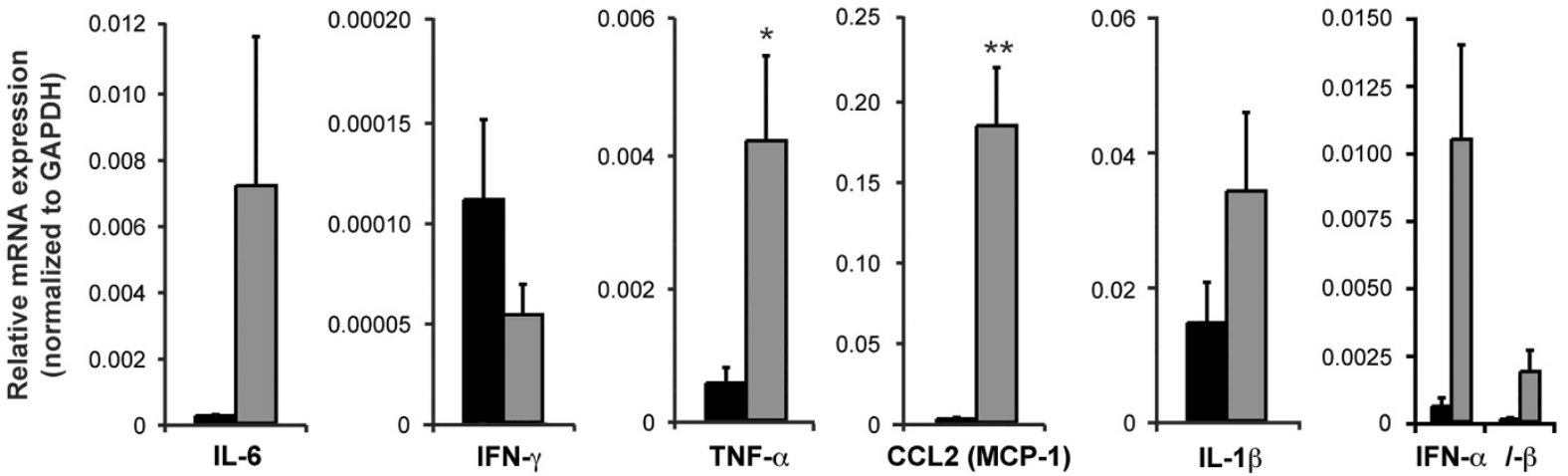

C

Wild type $\square$ FLIPf/f-creERT2
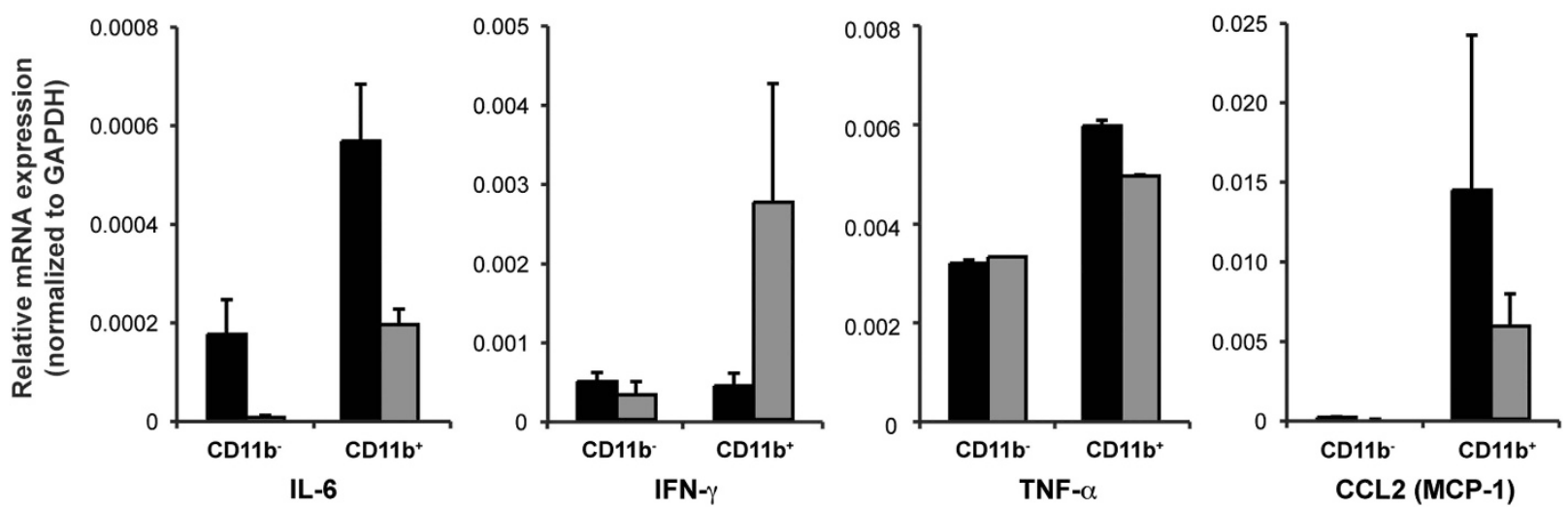

Figure 3 Deletion of cFLIP leads to an enhanced secretion of pro-inflammatory cytokines and the macrophage-attractant CCL2. (a) Serum cytokines and (b) their hepatic mRNA expression at $48 \mathrm{~h}$ were measured in tamoxifen-treated wt and FLIP/f - creERT2 mice. (c) CD11 $\mathrm{b}^{-}$and CD11 $\mathrm{b}^{+}$cells were isolated from spleen of wt and FLIP/f-creERT2 mice at $48 \mathrm{~h}$ following treatment with tamoxifen using CD11b MACS beads. mRNAs were purified and measured by qRT-PCR for relative IL-6, IFN- $\gamma$, TNF and CCL2 (MCP-1) mRNA expression. Data represent mean \pm S.E.M. (a-c: $n \geq 7$ mice/group), $P$-values for wt versus FLIPff -creERT2: ${ }^{*} P<0.05,{ }^{* *} P<0.01,{ }^{* \star *} P<0.001$

classically activated M1 phenotype. To investigate their contribution to acute liver failure, macrophages were depleted by pretreatment with liposome-encapsulated dichlormethylene diphosphonate (clodronate) or PBS $48 \mathrm{~h}$ before tamoxifen injection. ${ }^{14}$ Depletion of macrophages significantly ameliorated liver injury (Figure 4f) and prevented death, indicating that the observed injury is dependent on macrophage activation in the liver.

Preservation of cFLIP in hematopoietic cells protects from immune-mediated acute liver failure. To further substantiate the potential role of cFLIP in immunocompetent 
a

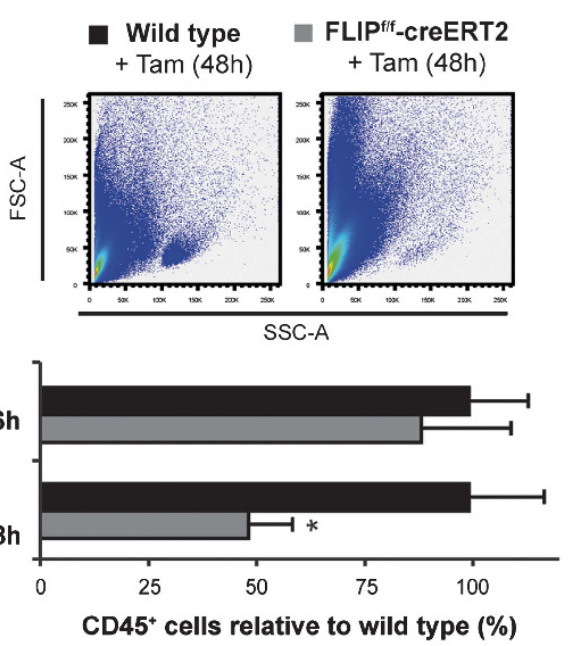

c

Wild type

口FLIP ${ }^{\text {fff-creERT2 }}$

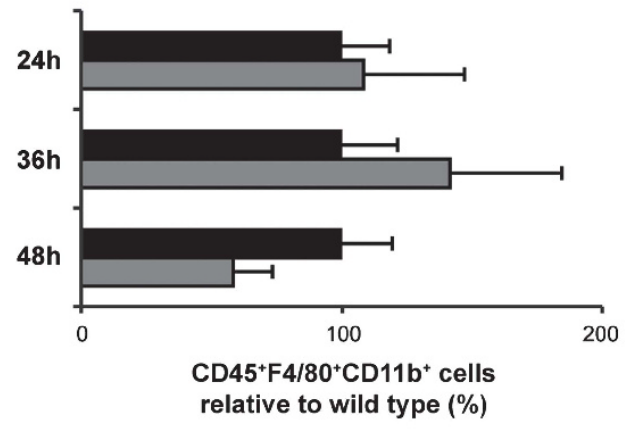

e

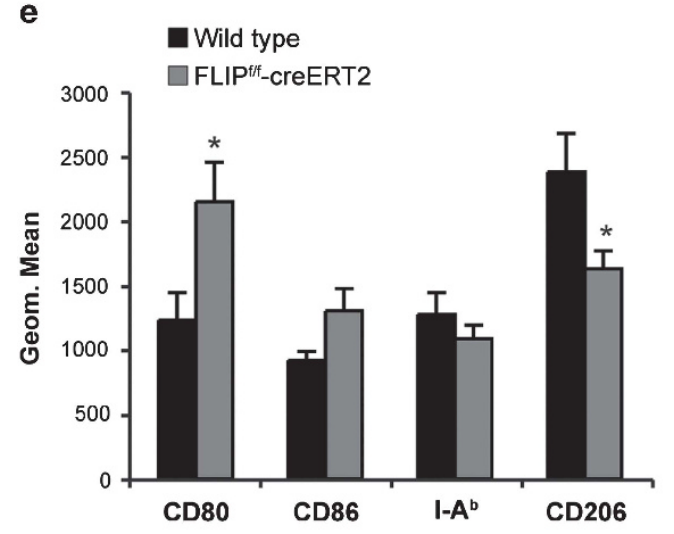

b
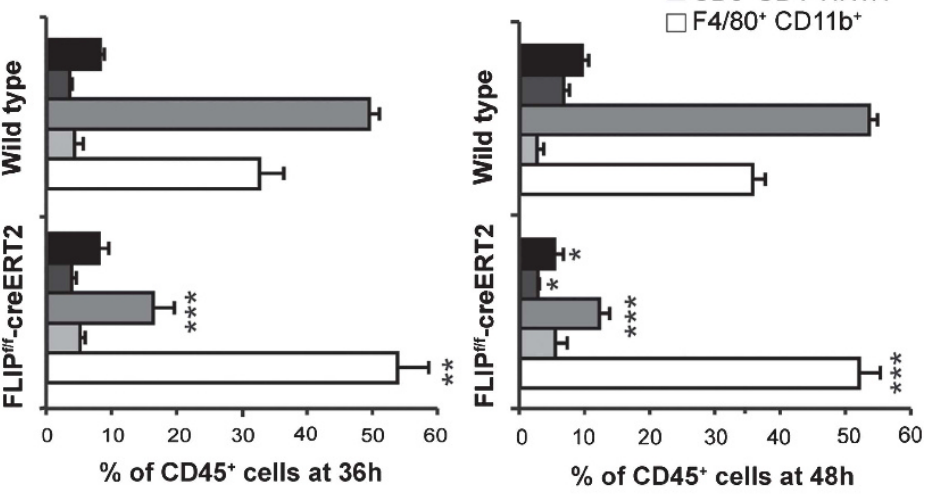

d

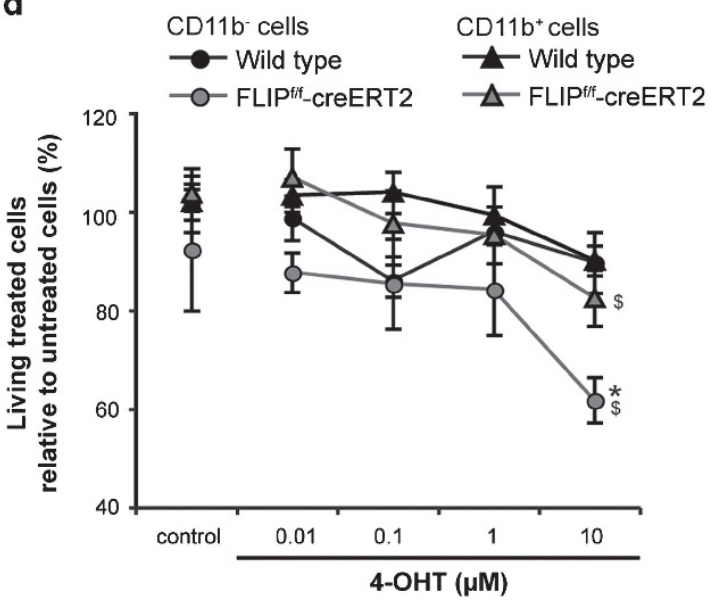

f

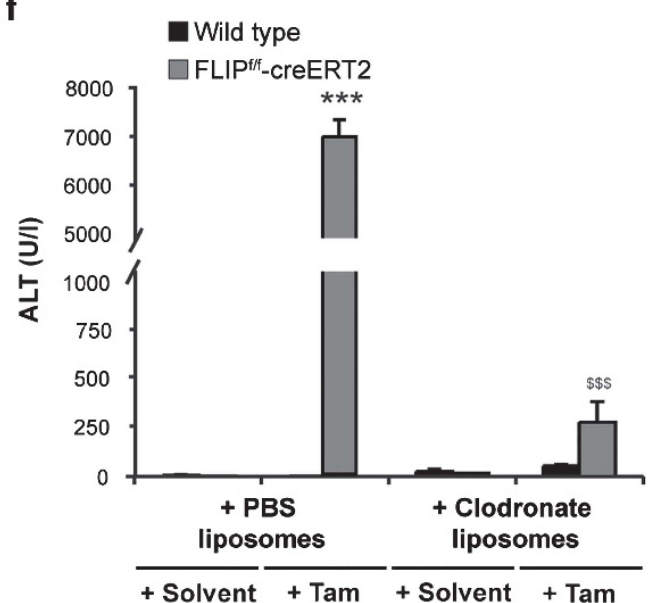

Figure 4 Loss of cFLIP induces apoptosis of intrahepatic T and B lymphocytes and activation of macrophages. (a) Living intrahepatic CD45 cells were quantified by flow cytometry. Numbers are expressed relative to tamoxifen-treated wt mice. A representative forward (FSC) and side scatter (SSC) plot is shown. (b) Intrahepatic leukocyte subsets were quantified by gating on $\mathrm{CD} 45^{+} \mathrm{CD} 3^{+} \mathrm{CD} 4^{+}$and $\mathrm{CD} 45^{+} \mathrm{CD} 3^{+} \mathrm{CD} 8^{+}$for $\mathrm{T}$ lymphocytes, $\mathrm{CD} 45^{+} \mathrm{CD} 3^{-} \mathrm{B} 22 \mathrm{O}^{+}$for $\mathrm{B}$ lymphocytes, $\mathrm{CD} 45^{+} \mathrm{CD} 3^{-} \mathrm{CD} 4^{-} \mathrm{NK} 1.1^{+}$for NK cells and $\mathrm{CD} 45^{+} \mathrm{F} 4 / 80^{+} \mathrm{CD} 11 \mathrm{~b}^{+}$for macrophages and quantitated relative to $\mathrm{CD} 45^{+}$cell numbers. (c) Intrahepatic macrophages were quantified by gating on living $\mathrm{CD} 45^{+} \mathrm{F} 4 / 80^{+} \mathrm{CD} 11 \mathrm{~b}^{+}$ cells. Numbers are expressed relative to tamoxifen-treated wt mice. (d) $\mathrm{CD}_{11 b^{-}}$and $\mathrm{CD} 11 \mathrm{~b}^{+}$cells were isolated from spleen of naive wt and FLIP ${ }^{\mathrm{ft}}$-creERT2 mice and stimulated for $48 \mathrm{~h}$ with different concentrations of 4-hydroxytamoxifen (4-OHT) as indicated or ethanol as a control. Cellular viability after deletion of cFLIP was quantified by Nicoletti assay. (e) Macrophages were characterized by M1/M2 markers. (f) Depletion of macrophages was achieved by clodronate-liposomes $48 \mathrm{~h}$ before tamoxifen. ALTwas determined at $48 \mathrm{~h}$. Data represent mean \pm S.E.M. (a-f: $n=5-14$ mice/group), $P$-values for wt versus FLIP ${ }^{\mathrm{f} / /}$-creERT2: ${ }^{*} P<0.05,{ }^{* *} P<0.01,{ }^{* * *} P<0.001$ and (d) for FLIP/f -creERT2 cells $\pm z V A D$ and (f) for FLIP/f/-creERT2 mice \pm clodronate liposomes: ${ }^{\$} P<0.05,{ }^{\$ \$} P<0.01,{ }^{\$ \$ \$} P<0.001$ 
cells during acute liver failure, chimeric mice were generated by transplantation BMC derived from wild-type mice into FLIP $^{\mathrm{f} / \mathrm{f}}$-creERT2 mice. Four weeks following the reconstitution, a chimerism of $80 \%$ was detectable (Supplementary results). Interestingly, chimeric FLIP $^{\mathrm{f} / \mathrm{f}}$-creERT2 mice carrying wild-type BMC exhibited significantly reduced ALT levels (Figure 5a) and did not develop hypoglycemia following tamoxifen treatment (Figure $5 \mathrm{~b}$ ). Additionally, activation of caspase 3 in liver, spleen and intestine (Figure 5c) and activation of JNK (Figure $5 d$ ) were prevented. Moreover, levels of TNF (Figure 5e), IL-6, IFN- $\gamma$ and CCL2 (Supplementary Figure 2A and C) were significantly reduced, indicating toward a protective role of wild-type BMC in acute liver failure following loss of cFLIP. The intrahepatic leukocyte populations following transplantation of wild-type BMC were not different as compared with non-transplanted FLIP $^{\mathrm{f} / \mathrm{f}}$ creERT2 mice before tamoxifen (data not shown), but following tamoxifen treatment the absolute number of $\mathrm{CD}_{4} 5^{+}$cells, especially B lymphocytes, was markedly enhanced in chimeric mice (Figure 5f). When comparing chimeric wild-type and FLIP $^{\mathrm{f} / \mathrm{f}}$-creERT2 mice post tamoxifen, the previously observed significant changes in T lymphocytes and macrophages were prevented by wild-type BMC (Supplementary Figure 2D). Only the percentage of intrahepatic B lymphocytes was still moderately reduced. These results suggest that concomitant deletion of cFLIP in hematopoietic cells and liver parenchymal cells is required for the induction of apoptosis and inflammation with resulting liver failure.

To further differentiate the involved cell types, BMC derived from FLIP/f -creERT2 were transferred into wild-type C57BL/6 mice. Interestingly, these chimeric mice did not develop endorgan injury following tamoxifen injection (Figure $5 \mathrm{~g}$ ), despite apoptosis in the spleen (data not shown). Likewise, transplantation of FLIP $^{\mathrm{f} / \mathrm{f}}$-creERT2 BMC in mice exhibiting a hepatocyte-restricted deletion of cFLIP (Alb-Cre:FLIP ${ }^{\mathrm{f} / \mathrm{f}}$ ) did not promote liver injury following tamoxifen injection (Figure 5g). Also, splenectomy did not protect from liver failure (data not shown). These data indicate that loss of cFLIP has to occur in more departments than leukocytes and hepatocytes.

The activation of macrophages in cFLIP-deficient mice is triggered by innate immune receptors. Since impairment of the intestinal barrier - for example, as a result of apoptosis of IECs - can promote the activation of TLR4, we evaluated the role of gut-derived endotoxins. Plasma endotoxin levels were markedly higher in FLIP $^{\mathrm{f} / \mathrm{f}}$-creERT2 mice as compared with wild-type mice at $48 \mathrm{~h}$ post tamoxifen (Figure 6a). In parallel, the expression levels of TLR4 and its adapter protein myeloid differentiation primary-response protein 88 (MyD88) were upregulated in their liver (Figure 6b). Gut decontamination by antibiotics ${ }^{15}$ led to a decrease in endotoxins and hepatic TLR4 expression (Figure $6 \mathrm{c}$ ), but resulted only in a slight reduction of ALT levels (Figure $6 d$ ). These findings argue against a major role of TLR4 in immune-mediated liver failure following loss of cFLIP.

Hepatic innate immunity can also be activated through the endosomal TLR9 and/or cytosolic DNA sensors including STING that respond to endogenous DAMPs including free genomic dsDNA. ${ }^{16,17}$ Indeed, we measured significantly increased amounts of cell-free DNA in the plasma of FLIP ${ }^{\mathrm{f} / \mathrm{f}}$ creERT2 mice at $48 \mathrm{~h}$ post tamoxifen as compared with wildtype controls (Figure 6e). In line with this, a marked upregulation of TLR9 expression (Figure 6f) as well as a significant increase in the expression of STING and its downstream effector TANK-binding kinase 1 (TBK1) occurred in their liver (Figure 6f), which was prevented by transplantation of wild-type BMC (Figure 6f). These observations suggest that acute liver failure after deletion of cFLIP is related to activation of immune and parenchymal cells, which are triggered by the release of DAMPs recognized by TLR9 and STING.

To underline the immune-stimulatory capacity of DAMPs in the blood of FLIP ${ }^{\mathrm{f} / \mathrm{f}}$-creERT2 mice after deletion of cFLIP, in vitro stimulation experiments were performed. To avoid an unspecific stimulation through mouse cytokines or other species-specific factors, the human macrophage-like cell line THP1 was chosen. PMA-differentiated THP1 cells released markedly enhanced amounts of IL-6 and TNF when incubated with serum from FLIP $^{\mathrm{f} / \mathrm{f}}$-creERT2 mice following tamoxifen treatment (Figure 6g). Furthermore, pretreatment of THP1 cells with chloroquine, an inhibitor of endosomal TLR activation by nucleic acids, was able to partially block immune stimulation. These data support a role of circulating DAMPs, especially cell-free dsDNA, in FLIP ${ }^{\mathrm{f} / \mathrm{f}}$-creERT2 mice which are sensed by several innate immune receptors of macrophages including TLR9 and STING.

\section{Discussion}

Tissue integrity is a crucial prerequisite for the survival of an organism and cell death mechanisms are tightly controlled by adapter proteins to prevent acute organ failure. Among these the caspase 8 homolog cFLIP was identified as critical regulator of apoptosis and necroptosis in different tissues and cell types. ${ }^{8,18,19}$ In the current study, we explored the function of cFLIP in overall tissue homeostasis by employing an inducible gene-knockout model, to avoid embryonic lethality and compensatory adaptations. Ubiquitous loss of cFLIP in mice led to a different phenotype compared with the hepatocyte-restricted deletion with fulminant liver failure and death within $96 \mathrm{~h}$. Apoptosis occurred in liver, spleen, kidney and intestine reflecting that these tissues are highly sensitive to caspase 8-mediated apoptosis and indicating the crucial role of cFLIP in tissue homeostasis in these organs. ${ }^{4,10,19,20}$ Liver injury was dependent on caspases and accompanied by activation of JNK, a critical regulator of TNF- and caspasemediated apoptosis. ${ }^{21}$ Other forms of cell death were unaffected. ${ }^{22,23}$ Previous studies have observed an important contribution of programmed necrosis in Alfp- and Mx1-Cre transgenic models, which was not observed to the same extent herein and likely reflect differences in the different animal models used. ${ }^{10}$

The onset of liver injury was preceded by increasing concentrations of inflammatory cytokines/chemokines including IL-6, IFN- $\gamma$, TNF and CCL2 in serum. Interestingly, their expression, in addition to IL- $1 \beta$ and IFN- $\alpha / \beta$ but not IFN- $\gamma$ occurred specifically in the liver but not in the spleen. IL- 6 is a macrophage and $\mathrm{T}$ cell-derived multifunctional cytokine with both pro- and anti-inflammatory actions, whereas the 
a

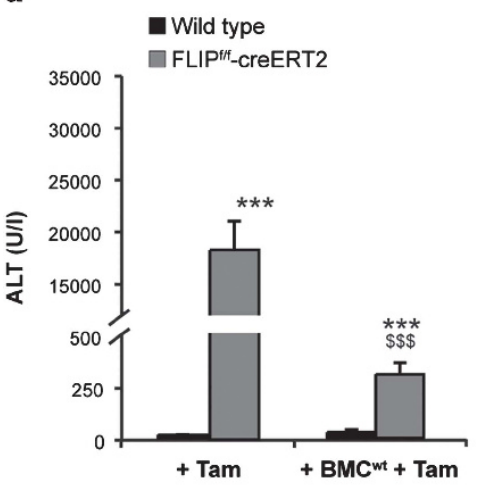

d

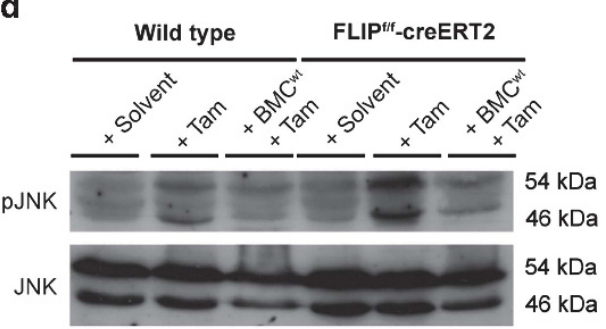

f
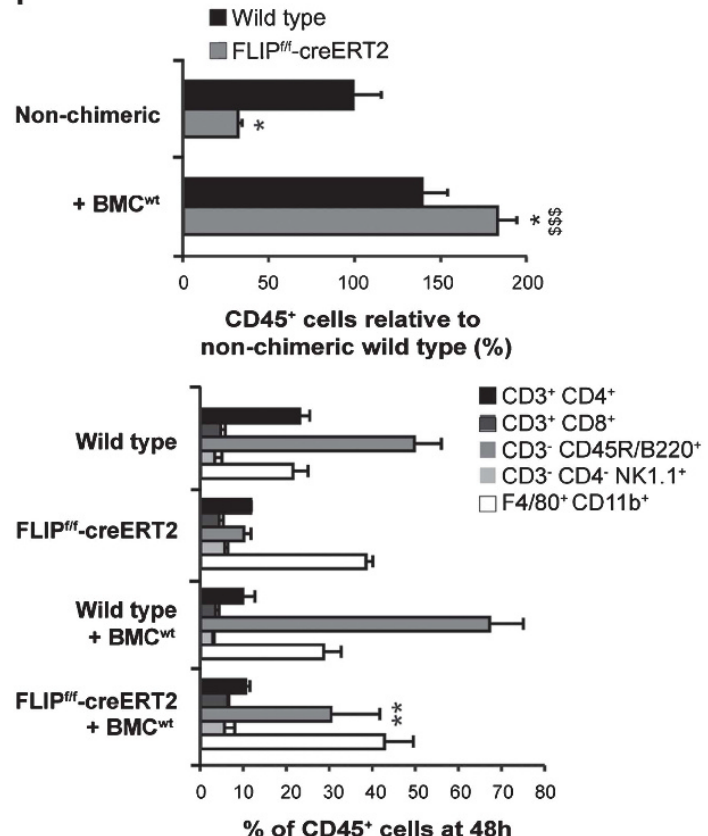

b

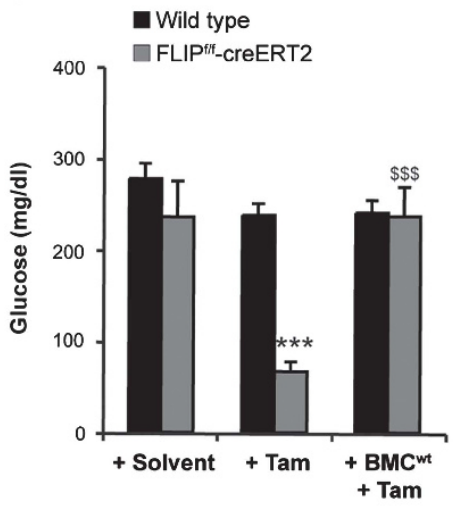

c

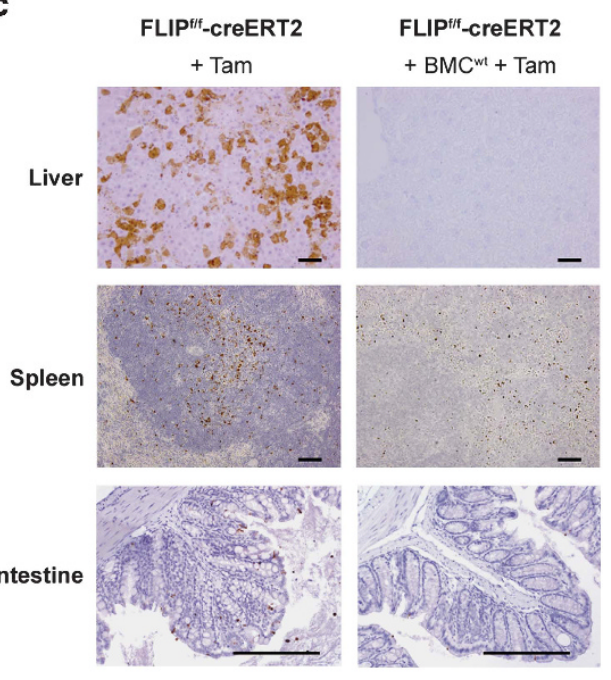

e

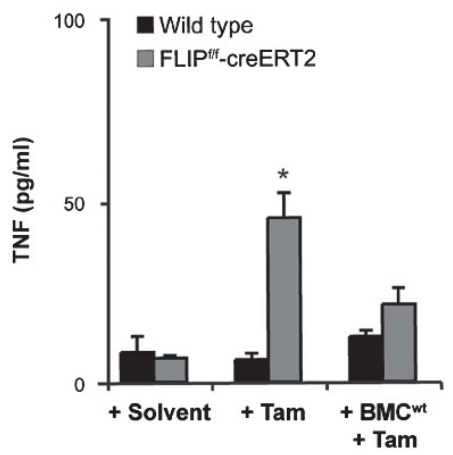

g

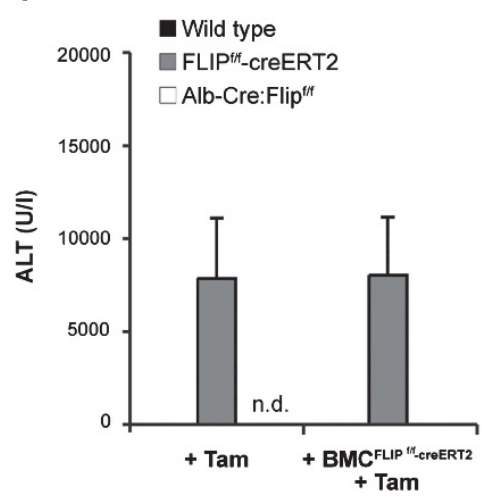

Figure 5 Transplantation of bone marrow cells with intact cFLIP protects from acute liver injury. Wt and FLIP/f - creERT2 mice transplanted with wt bone marrow cells (BMC ${ }^{\text {wt }}$ ). (a) ALT, (b) blood glucose, (c) activated-caspase 3 in liver, spleen and intestine (scale bar: $2000 \mu \mathrm{m}$ ), (d) phosphorylation of JNK in liver lysates, (e) serum TNF and (f) quantification of intrahepatic CD45 $5^{+}$cells and subsets in their liver at $48 \mathrm{~h}$ post tamoxifen. (g) ALT in mice transplanted with BMC derived from FLIP/f-creERT2 mice $\left(B M C^{\text {FLIPfff }- \text { creERT2 }}\right.$ ) at $48 \mathrm{~h}$ post tamoxifen (n.d. = not determined). Data represent mean \pm S.E.M. $(a-g: n=7-16$ mice/group), $P$-values for wt versus FLIP/f -creERT2: ${ }^{\star} P<0.05,{ }^{\star \star} P<0.01,{ }^{\star * \star} P<0.001$ and for FLIP ${ }^{f / t}$-creERT2 cells \pm BMC ${ }^{\text {wt. }}:{ }^{\$} P<0.05,{ }^{\$ \$} P<0.01,{ }^{\$ \$} P<0.001$ 
a

a

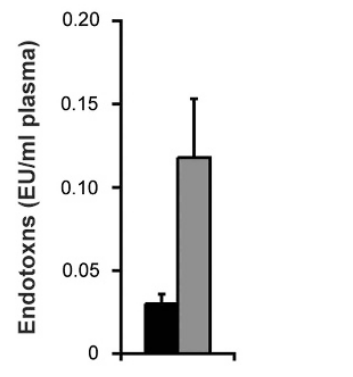

d

Wild type $\square$ FLIPfff-creERT2

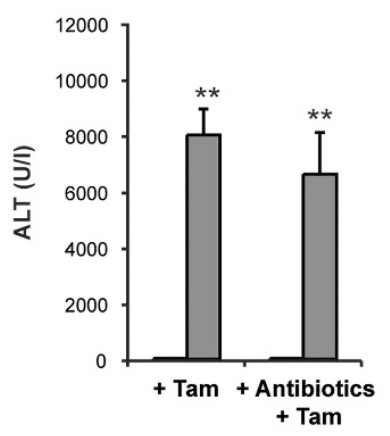

g

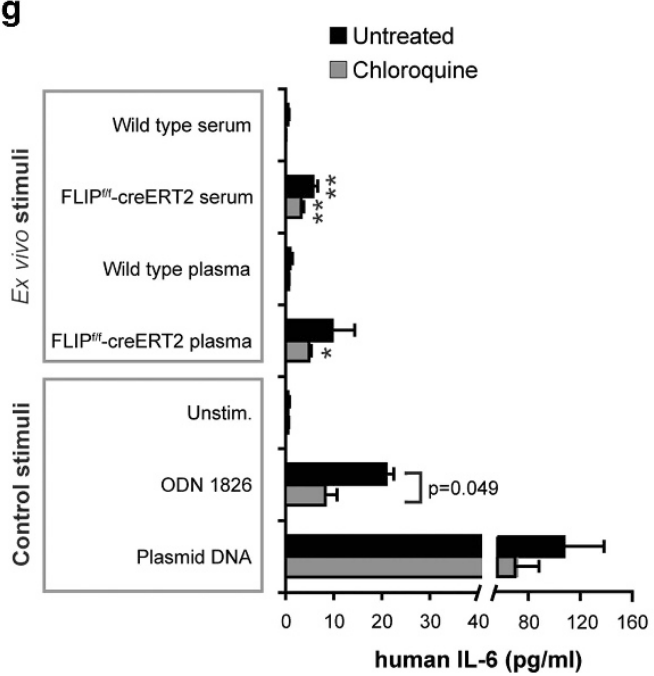

e

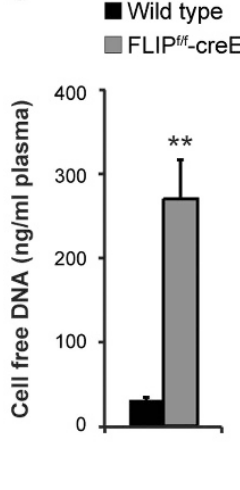

b

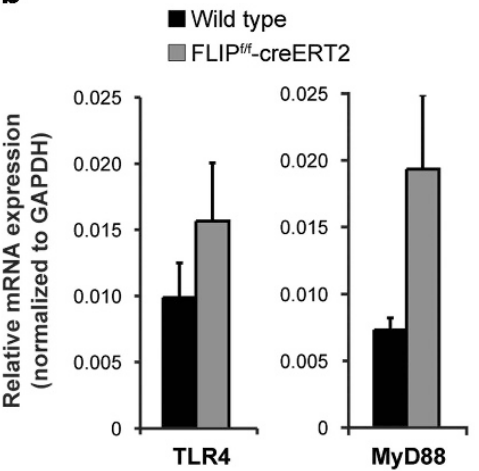

C
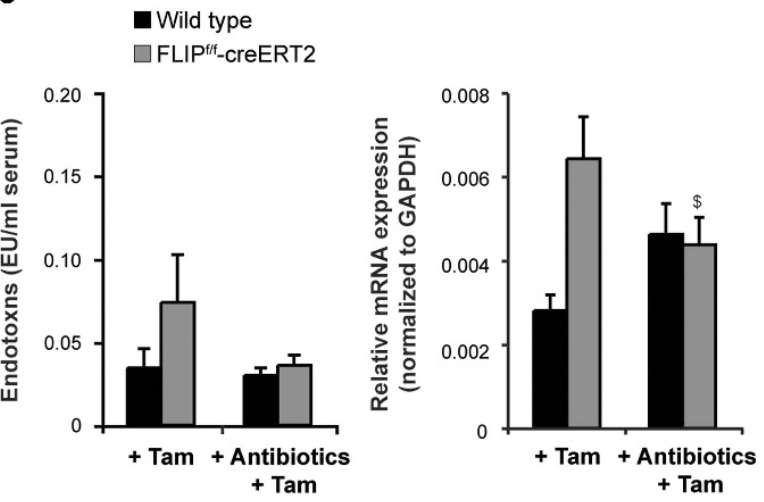

TLR4

f

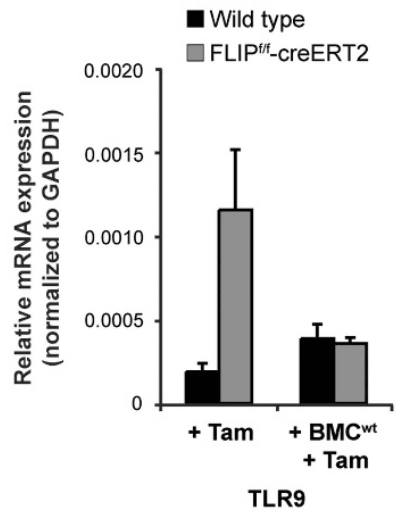

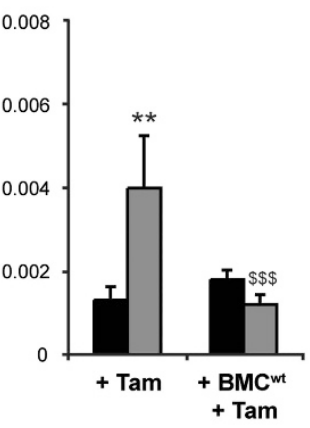

STING

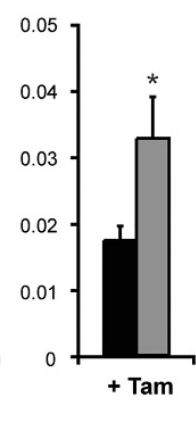

TBK1

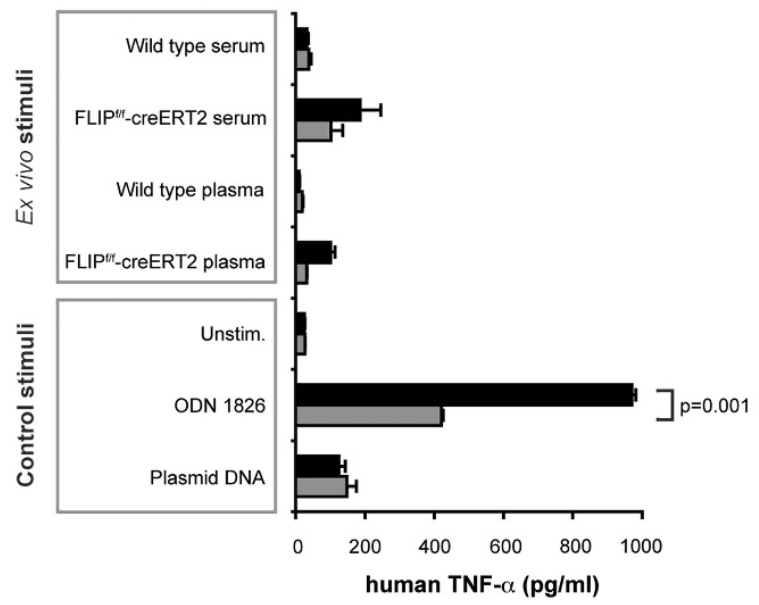

Figure 6 Acute liver failure in FLIPf/f-creERT2 mice is induced through activation of innate immune receptors. (a) Endotoxin levels were determined in the plasma of wt and FLIP/f -creERT2 mice at $48 \mathrm{~h}$ following injection of tamoxifen. (b) Hepatic mRNAs isolated from wt and FLIP ${ }^{\mathrm{f} / \mathrm{t}}$-creERT2 mice at $48 \mathrm{~h}$ post tamoxifen were measured by qRT-PCR for relative TLR4 and MyD88 mRNA expression. (c) After 4 weeks of gut decontamination endotoxin levels in the serum, hepatic mRNA expression of TLR4 and (d) ALT levels was determined at $48 \mathrm{~h}$ post tamoxifen. (e) Cell-free DNA was measured photometrically in the plasma of wt and FLIP ${ }^{\mathrm{ff}}$-creERT2 mice at $48 \mathrm{~h}$ following injection of tamoxifen. (f) Relative mRNA expression of TLR9, STING and TBK1 was determined in liver from induced mice \pm BMC $^{\text {wt }}$. (g) Human PMA-differentiated THP1 cells with or without chloroquine pretreatment $(10 \mu \mathrm{M})$ were stimulated with serum or plasma of induced wt and FLIP $P^{\mathrm{ff}}$-creERT2 mice. The TLR9 ligand ODN 1826 and plasmid DNA as STING ligand were used as controls. After 18-24 h, the secretion of IL-6 and TNF was measured in the supernatants. Data represent mean \pm S.E.M. (a-f: $n \geq 6$ mice/group, g: of three independent experiments each in triplicate), $P$-values for wt versus FLIP/f -creERT2: ${ }^{*} P<0.05,{ }^{\star \star} P<0.01,{ }^{\star \star \star} P<0.001$ and for FLIP/f -creERT2 cells \pm BMC ${ }^{\mathrm{wt}}$. ${ }^{\$} P<0.05$, $\$ \$ P<0.01,{ }^{\$ \$} P<0.001$ 
inflammatory IFN- $\gamma$, which is released by T cells, NK cells and macrophages, contributes to liver injury by the upregulation of Fas on hepatocytes, rendering them susceptible to apoptotic cell death, ${ }^{24}$ and stimulation of hepatic macrophages. Likewise, TNF is known to enhance the production of other proinflammatory cytokines, to provoke cellular recruitment to sites of injury and to induce hepatocellular apoptosis. ${ }^{25}$ Macrophage-secreted IL- $1 \beta$ attracts neutrophils, which are capable of inducing oxidative injury and death of hepatocytes. ${ }^{26}$

In line with the observed cytokine pattern and despite an absolute reduction in intrahepatic $\mathrm{CD}_{4} 5^{+}$cells, a relative increase in NK cells and in particular of macrophages occurred selectively in the liver, but not in peripheral blood or spleen. Interestingly, we observed a decreased sensitivity of macrophages to undergo apoptosis following cFLIP deletion and accumulation of these cells in the liver could be related to a prolonged survival. Also we observed an upregulation of CCL2. The origin of hepatic CCL2 in acute liver injury is known to be both resident Kupffer cells and injured hepatocytes leading to the recruitment of monocytes/macrophages, NK cells, $\mathrm{T}$ cells and neutrophil granulocytes. ${ }^{27}$ Moreover, hepatic-derived CCL2 is able to stimulate the expansion, mobilization and subsequent trafficking of bone marrow population of activated $\mathrm{CD} 11 \mathrm{~b}^{+} \mathrm{F} 4 / 80^{+}$monocytes/macrophages to the liver, accounting for the marked expansion in hepatic macrophage numbers seen after acute liver injury. ${ }^{28}$ Pro-inflammatory, M1-polarized macrophages can contribute to the recruitment of additional inflammatory and other immune cells into the tissue, while M2-polarized macrophages are predominantly anti-inflammatory. ${ }^{26}$ Loss of cFLIP was accompanied by a shift in the polarization toward a M1 subpopulation of macrophages. Strikingly, depletion of macrophages prevented liver injury and mortality. These results point toward a mechanistic involvement of pro-inflammatory macrophages in the context of lethal organ failure following loss of cFLIP. These macrophages do not seem to be generally more prone to activation than wild-type macrophages. Nonetheless, a strong activation occurs following loss of cFLIP through the high degree of apoptosis of leukocytes, in particular lymphocytes, hepatocytes and potentially other non-parenchymal cells and the emergence of released DAMPs, which triggers inflammatory signaling and finally more tissue injury. Also, the data of Piao et al. ${ }^{10}$ suggests that death ligands produced by Kupffer cells may be responsible for hepatotoxicity. However, it remained unclear which mechanisms were involved in the activation of Kupffer cells.

Induction of apoptosis - particularly in hematopoietic cells was a crucial event that preceded liver failure, because in contrast to previous studies ${ }^{10}$ mice were rescued by transplantation of wild-type BMC that retained cFLIP suggesting that concomitant ablation of cFLIP in hematopoietic cells and hepatocytes is required for organ failure. In line with this, compound deletion of cFLIP in hepatocytes and hematopoietic cells did not result in liver injury either, despite apoptosis in the spleen, indicating that potentially other non-parenchymal cells in the liver, for example, hepatic endothelial cells or stellate cells contribute to the observed phenotype. Sinusoidal endothelia cells are already known as a critical regulator of liver failure in response to Fas/CD95 activation. ${ }^{24}$ Indeed, two different endothelial markers (CD31 and FcgammaRIIb) were strikingly downregulated in hepatic tissue following deletion of cFLIP. It remains to be determined whether a differential sensitivity of these cells to undergo apoptosis following the deletion of cFLIP and thus the relative cellular composition, resp. ratio of parenchymal and non-parenchymal cells in the liver at one time point potentially contributes to the observed phenotype. Overall, these findings suggests an organspanning immune activation inducing acute liver failure and extend previous observation of the lethal phenotype following deletion of cFLIP in IECs or a combination of hepatocytes and IECs. ${ }^{4,10}$

Ample evidence links gut-derived LPS and TLR4 signaling to liver injury and inflammation. ${ }^{29}$ Interestingly, TLR4 is required both on parenchymal and on hematopoietic derived cells for liver injury in the context of NASH indicating that these compartments synergize in the induction of liver injury. ${ }^{30}$ Despite the involvement of TLR4 and elevated levels of plasma endotoxins, selective gut decontamination was not sufficient to block liver injury implying that other mechanisms may coexist. Also, data by Wittkopf et al. ${ }^{4}$ support this hypothesis. Here we identified TLR9 and STING to be critically involved as sensors of free genomic dsDNA released during cell death. ${ }^{31}$ The importance of TLR9 for the sensing of DNA from apoptotic hepatocytes and subsequent liver damage was already shown by Watanabe et al. $^{32}$ In line with this, STINGIRF3 signaling has recently been implied in alcoholic liver disease and STING deficiency prevented interferon regulatory transcription factor (IRF) 3-mediated mitochondrial hepatocellular apoptosis. ${ }^{33}$ In this context, cytosolic dsDNA, which activates STING via cGMP-AMP synthase (cGAS), has been suggested to be crucial for cell death in vitro. ${ }^{34}$ dsDNA is normally non-immunogenic due to its rapid extracellular degradation and intracellular presence of DNA recognizing receptors. However, under pathophysiological conditions these protective mechanisms are abrogated and dsDNA becomes immunogenic. ${ }^{35,36}$ In the current study, we were able to detect significant elevated amounts of cell-free DNA in the blood of mice following loss of cFLIP.

Furthermore, we demonstrate for the first time that besides TLR9 STING and its downstream molecule TBK1 becomes upregulated in the context of apoptosis induction in the liver, in parallel to the IFN- $\alpha / \beta$ and inflammatory cytokines response and thus contributes to the lethal inflammatory immune response after deletion of cFLIP. IFN- $a$ is only induced following recognition of nucleic acids, for example, released by dying or dead cells. IFN- $\alpha$ and $-\beta$ are capable of causing hepatic injury and liver failure due to apoptosis induction, release of cytokines (e.g., CCL2, IFN- $\gamma$ and IL-12) and leukocyte recruitment. The stimulatory capacity of DAMPs, including cell-free DNA, in murine blood following cFLIPdeletion was underlined by in vitro studies using human macrophage-like THP1 cells. Herein, a serum transmissive factor induced macrophage activation and the release of inflammatory cytokines even across species. In this context, Canbay et al. ${ }^{37}$ have previously shown that engulfment of apoptotic hepatocytes by Kupffer cells stimulates death ligand and cytokine expression. However, our in vitro studies with chloroquine also underline the involvement of several innate immune receptors. We cannot rule out that besides TLR9 and 
STING other receptors in particular endosomal and cytosolic RNA sensors are activated by circulating DAMPs.

In summary, acute organ failure in the context of decreased cFLIP expression commences by DAMP-triggered inflammation and activation of immunocompetent cells - particularly macrophages - in different tissues and especially the liver. This involves innate immune receptors that sense circulating DAMPs, including cell-free DNA, and enhance cellular apoptosis in a positive feed-forward loop by stimulating the expression of cytokines and death ligands (summarized in Figure 7). These results support therapeutic strategies that include selective inhibition of pro-inflammatory macrophages or their sensing of DAMPs to prevent apoptosis and potentially improve survival in patients with acute organ failure.

\section{Materials and Methods}

Animal models. All animals were bred at the animal facility of the University Medical Center Mainz, according to the criteria outlined by the 'Guide for the Care and Use of Laboratory Animals' and studies were approved by the committee for experimental animal research (Landesuntersuchungsamt Rheinland-Pfalz). Mice expressing the cre-recombinase under control of a tamoxifen-sensitive estrogen receptor (ROSA26-creERT2) ${ }^{11}$ were crossed with mice carrying lox-P sites flanking the Exon 1 in the cFLIP gene. ${ }^{8}$ Offspring, homozygous for floxed cFLIP and positive for cre-transgene (FLIP/t-creERT2), were compared with cre-negative littermates that are referred to as wild type (wt). Deletion of CFLIP in 8- to 12-week-old mice was achieved by intraperitoneal (i.p.) injection of $2 \mathrm{mg}$ tamoxifen (Sigma-Aldrich, Steinheim, Germany) dissolved in olive oil. Additionally, mice with a constitutive hepatocyte-specific deletion of cFLIP using albumin driven cre-expression (Alb-Cre: FLIP $^{\mathrm{t} / 5}$ ) were analyzed. ${ }^{5}$

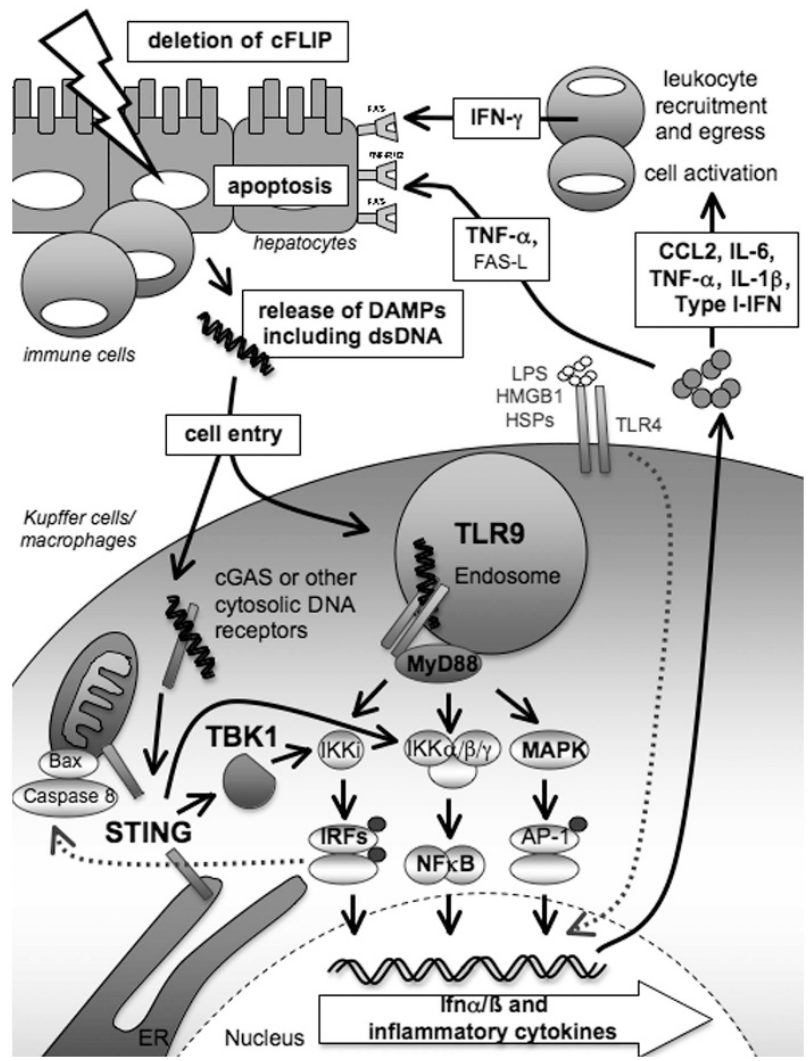

Figure 7 Model of acute liver failure from activation of innate immune receptors by DAMPs released from dying or dead cells following deletion of CFLIP
Generation of chimeric mice by bone marrow transplantation. For bone marrow transplantation, $2 \times 10^{6}-1 \times 10^{7}$ bone marrow cells (BMC) derived from wild-type or FLIP/f-creERT2 mice were injected through the tail vein following lethal irradiation $(2 \times 6.5 \mathrm{~Gy} ; 3 \mathrm{~h})$. Further experiments were performed 4 weeks post reconstitution. The effectiveness of bone marrow transplantation was assessed after exposure to a myeloablative dose of $\gamma$-irradiation and transplantation of bone marrow derived from CD45.1 (Ly5.1) C57BL/6 mice into CD45.2 C57BL/6 mice. Four weeks following transplantation, $80 \%$ of the immune cells in the liver of chimeric mice were CD45.1 positive. Interestingly, CD45.2-positive macrophages could still be identified in their liver (data not shown).

Histological analyses and immunohistochemistry. Samples derived from liver, spleen, kidney, intestine, heart and brain were fixed in $4 \%$ paraformaldehyde, embedded in paraffin, and stained with hematoxylin and eosin (H\&E). For in situ detection of apoptotic cells, terminal dUTP nick-end labeling (TUNEL, Roche, Mannheim, Germany) was performed. Immunohistochemistry for activated caspases 3, 8 and 9 (all from Cell Signaling Technology Inc., Danvers, MA, USA), CFLIP (ProSci Inc., Poway, CA, USA) and macrophages (F4/80, Acris Antibodies, San Diego, CA, USA) was performed as previously described. ${ }^{5}$

Quantitative analysis of cytokines and chemokines. Concentrations of serum cytokines were measured by cytometric bead array (CBA), Mouse Th1/ Th2 Cytokine Kit and Mouse Inflammation Kit (BD Biosciences, Heidelberg, Germany) using a BD FACS Canto II flow cytometer (BD Biosciences). Analysis was performed by the FCAP Array v3 Analysis software (Soft Flow, St. Louis Park, MN, USA). IL-6 and TNF in the supernatants of the human cell line THP1 were analyzed by Human IL-6 and TNF ELISA Ready-SET-Go! (eBioscience, San Diego, CA, USA).

Cell isolation, stimulation and flow-cytometric analysis. Isolation of intrahepatic immune cells and their flow-cytometric analysis (FACS) were performed as previously described. ${ }^{5} \mathrm{CD}_{11 \mathrm{~b}^{-}}$and $\mathrm{CD} 11 \mathrm{~b}^{+}$splenocytes were isolated following mechanical disruption of the organ and erythrolysis and were separated using CD11b MACS beads (Miltenyi Biotec, Bergisch Gladbach, Germany). When indicated, cells were cultured with 4-hydroxytamoxifen (4-OHT, Sigma-Aldrich) dissolved in ethanol for $48 \mathrm{~h}$ at the indicated concentration. Evaluation by FACS showed that the CD11 $\mathrm{b}^{-}$cell fraction consisted of on average $88 \% \mathrm{~T}$ and $\mathrm{B}$ lymphocytes, whereas the $\mathrm{CD} 11 \mathrm{~b}^{+}$fraction was significantly enriched with monocytes/macrophages in addition to dendritic cells and NK cells (68\%) (data not shown).

Human THP1 cells were cultured in RPMI-1640 supplemented with 10\% FCS, $2 \mathrm{mM}$ L-glutamine, $0.1 \mathrm{mM}$ MEM non-essential amino acids, $1 \mathrm{mM}$ MEM sodium pyruvate and $100 \mathrm{U} / \mathrm{ml}$ penicillin/streptomycin (all from Gibco, Grand Island, NY, USA). For differentiation, PMA (Sigma-Aldrich) was added at a concentration of $300 \mathrm{ng} / \mathrm{ml}$ for $3-4 \mathrm{~h}$. Cells were then harvested, centrifuged, washed twice and plated at a concentration of $1 \times 10^{6}$ cells $/ \mathrm{ml}$ experimentation after $24 \mathrm{~h}$. Pretreatment $(1 \mathrm{~h})$ with or without chloroquine (10 $\mu \mathrm{M}$, Sigma-Aldrich) preceded the incubation with a $1: 20$ dilution of murine serum or plasma for $24 \mathrm{~h}$. For control, cells were transfected with CpG ODN 1826 (InvivoGen, San Diego, CA, USA) or plasmid DNA ( $3 \mu \mathrm{g} / \mathrm{ml})$ complexed with SuperFect Transfection Reagent (Qiagen, Hilden, Germany) according to the manufacturer's instructions.

Quantitative real-time PCR. Isolation of total RNA, cDNA synthesis and qRT-PCR were performed as previously described. ${ }^{5}$ Roche LightCycler software (LightCycler 480 Software Release 1.5.0) was used to perform advanced analysis relative quantification using the $2^{(-\Delta \Delta(\mathrm{T}))}$ method. Expression data were normalized to the housekeeping gene GAPDH. Primer sequences are listed in Supplementary Table 1.

Statistical analysis. Values are given as mean \pm standard error of the mean (S.E.M.) and represent data from a minimum of three independent experiments. The F-test was used to verify the assumption of equal variances, and two-tailed Student's $t$-test was used to determine statistical significance. Statistically significant values are presented as: ${ }^{* / \$} P<0.05,{ }^{* * / \$ \$} P<0.01,{ }^{* * * \$ \$ \$} P<0.001$.

\section{Conflict of Interest}

The authors declare no conflict of interest. 
Acknowledgements. Irina Wagner, Brigitte Bartsch, Sonja Klein, Sandra Schmidt and Christine Waldmann contributed with excellent technical assistance and P. Simon (Department of Sports Medicine, Prevention and Rehabilitation, University Mainz) for support with dsDNA measurements. JMS received funding from the Deutsche Forschungsgemeinschaft (DFG (SCHA 1015/3-1), Deutsche Krebshilfe (Grant Number: 110994), and support of intramural funds of the Johannes-Gutenberg University Mainz. MS received funding from the DFG (SCHU 1239/3-1).

\section{Author contributions}

This manuscript contains parts of the doctoral thesis of DGB at the Johannes Gutenberg University Mainz.

1. Suzanne M, Steller H. Shaping organisms with apoptosis. Cell Death Differ 2013; 20: 669-675.

2. Lavrik IN, Krammer PH. Regulation of CD95/Fas signaling at the DISC. Cell Death Differ 2012; 19: 36-41.

3. Yeh WC, Itie A, Elia AJ, Ng M, Shu HB, Wakeham A et al. Requirement for Casper (c-FLIP) in regulation of death receptor-induced apoptosis and embryonic development. Immunity 2000 12: $633-642$

4. Wittkopf N, Günther C, Martini E, He G, Amann K, He YW et al. Cellular FLICE-like inhibitory protein secures intestinal epithelial cell survival and immune homeostasis by regulating caspase-8. Gastroenterology 2013; 145: 1369-1379.

5. Schattenberg J M, Zimmermann T, Wörns M, Sprinzl MF, Kreft A, Kohl T et al. Ablation of c-FLIP in hepatocytes enhances death-receptor mediated apoptosis and toxic liver injury in vivo. J.Hepatol 2011; 55: 1272-1280.

6. Schattenberg J M, Nagel M, Kim YO, Kohl T, Wörns MA, Zimmermann T et al. Increased hepatic fibrosis and JNK2-dependent liver injury in mice exhibiting hepatocyte-specific deletion of CFLIP. Am J Physiol Gastrointest Liver Physiol 2012; 303: G498-G506.

7. Liedtke C, Bangen JM, Freimuth J, Beraza N, Lambertz D, Cubero FJ et al. Loss of caspase-8 protects mice against inflammation-related hepatocarcinogenesis but induces non-apoptotic liver injury. Gastroenterology 2011; 141: 2176-2187.

8. Zhang N, He Y W. An essential role for c-FLIP in the efficient development of mature $T$ lymphocytes. J Exp Med 2005; 202: 395-404.

9. Roca H, Varsos ZS, Sud S, Craig MJ, Ying C, Pienta KJ et al. CCL2 and interleukin-6 promote survival of human $\mathrm{CD} 11 \mathrm{~b}+$ peripheral blood mononuclear cells and induce M2-type macrophage polarization. J Biol Chem 2009; 284: 34342-34354.

10. Piao X, Komazawa-Sakon S, Nishina T, Koike M, Piao JH, Ehlken $\mathrm{H}$ et al. c-FLIP maintains tissue homeostasis by preventing apoptosis and programmed necrosis. Sci Signal 2012; 5: ra93

11. Hameyer D, Loonstra A, Eshkind L, Schmitt S, Antunes C, Groen A et al. Toxicity of ligand-dependent $\mathrm{Cre}$ recombinases and generation of a conditional Cre deleter mouse allowing mosaic recombination in peripheral tissues. Physiol Genomics 2007; 31: 32-41.

12. Schattenberg J M, Singh R, Wang Y, Lefkowitch JH, Rigoli RM, Scherer PE et al. JNK1 but not JNK2 promotes the development of steatohepatitis in mice. Hepatology 2006; 43 . 163-172.

13. Kluwe J, Pradere JP, Gwak GY, Mencin A, De Minicis S, Osterreicher $\mathrm{CH}$ et al. Modulation of hepatic fibrosis by c-Jun-N-terminal kinase inhibition. Gastroenterology 2010; 138: 347-359.

14. van Rooijen N, Hendrikx E. Liposomes for specific depletion of macrophages from organs and tissues. Methods Mol Biol 2010; 605: 189-203.

15. Rakoff-Nahoum S, Paglino J, Eslami-Varzaneh F, Edberg S, Medzhitov R. Recognition of commensal microflora by toll-like receptors is required for intestinal homeostasis. Cell 2004; 118: 229-241.

16. Seki E, Brenner D A. Toll-like receptors and adaptor molecules in liver disease: update. Hepatology 2008; 48: 322-335
17. Gehrke N, Mertens C, Zillinger T, Wenzel J, Bald T, Zahn S et al. Oxidative damage of DNA confers resistance to cytosolic nuclease TREX1 degradation and potentiates STING-dependent immune sensing. Immunity 2013; 39: 482-495.

18. Guicciardi ME, Malhi H, Mott JL, Gores GJ. Apoptosis and necrosis in the liver. Compr Physiol 2013; 3: 977-1010

19. Gunther C, Martini E, Wittkopf N, Amann K, Weigmann B, Neumann H et al. Caspase-8 regulates TNF-alpha-induced epithelial necroptosis and terminal ileitis. Nature 2011; 477: 335-339.

20. Du C, Guan Q, Yin Z, Zhong R, Jevnikar AM. IL-2-mediated apoptosis of kidney tubular epithelial cells is regulated by the caspase-8 inhibitor c-FLIP. Kidney Int 2005; 67: 1397-1409.

21. Wang Y, Singh R, Lefkowitch JH, Rigoli RM, Czaja MJ. Tumor necrosis factor-induced toxic liver injury results from JNK2-dependent activation of caspase-8 and the mitochondrial death pathway. J Biol Chem 2006; 281: 15258-15267.

22. He MX, He YW. A role for $\mathrm{c}-\mathrm{FLIP}(\mathrm{L})$ in the regulation of apoptosis, autophagy, and necroptosis in T lymphocytes. Cell Death Differ 2013; 20: 188-197.

23. Vucur M, Reisinger F, Gautheron J, Janssen J, Roderburg C, Cardenas DV et al. RIP3 inhibits inflammatory hepatocarcinogenesis but promotes cholestasis by controlling caspase-8- and JNK-dependent compensatory cell proliferation. Cell Rep 2013; 4: 776-790.

24. Xu Y Szalai AJ, Zhou T, Zinn KR, Chaudhuri TR, Li X et al. Fc gamma Rs modulate cytotoxicity of anti-Fas antibodies: implications for agonistic antibody-based therapeutics. J Immunol 2003; 171: 562-568.

25. Possamai LA, Antoniades CG, Anstee QM, Quaglia A, Vergani D, Thursz M et al. Role of monocytes and macrophages in experimental and human acute liver failure. World J Gastroenterol 2010; 16: 1811-1819.

26. Zimmermann HW, Trautwein C, Tacke F. Functional role of monocytes and macrophages for the inflammatory response in acute liver injury. Front Physiol 2012; 3: 56

27. Dambach DM, Watson LM, Gray KR, Durham SK, Laskin DL. Role of CCR2 in macrophage migration into the liver during acetaminophen-induced hepatotoxicity in the mouse. Hepatology 2002; 35: 1093-1103.

28. Karlmark KR, Wasmuth HE, Trautwein C, Tacke F. Chemokine-directed immune cell infiltration in acute and chronic liver disease. Expert Rev Gastroenterol Hepatol 2008; 2: 233-242.

29. Takeuchi O, Akira S. Pattern recognition receptors and inflammation. Cell 2010; 140: 805-820.

30. Inokuchi S, Tsukamoto H, Park E, Liu ZX, Brenner DA, Seki E et al. Toll-like receptor 4 mediates alcohol-induced steatohepatitis through bone marrow-derived and endogenous liver cells in mice. Alcohol Clin Exp Res 2011; 35: 1509-1518.

31. Mencin A, Kluwe J, Schwabe RF. Toll-like receptors as targets in chronic liver diseases. Gut 2009; 58: 704-720.

32. Watanabe A, Hashmi A, Gomes DA, Town T, Badou A, Flavell RA et al. Apoptotic hepatocyte DNA inhibits hepatic stellate cell chemotaxis via toll-like receptor 9. Hepatology 2007; 46: 1509-1518.

33. Petrasek J, Iracheta-Vellve A, Csak T, Satishchandran A, Kodys K, Kurt-Jones EA et al. STING-IRF3 pathway links endoplasmic reticulum stress with hepatocyte apoptosis in early alcoholic liver disease. Proc Natl Acad Sci USA 2013; 110: 16544-16549.

34. Sun L, Wu J, Du F, Chen X, Chen ZJ. Cyclic GMP-AMP synthase is a cytosolic DNA sensor that activates the type I interferon pathway. Science 2013; 339: 786-791.

35. Lande R, Gregorio J, Facchinetti V, Chatterjee B, Wang YH, Homey B et al. Plasmacytoid dendritic cells sense self-DNA coupled with antimicrobial peptide. Nature 2007; 449: 564-569.

36. Chamilos G, Gregorio J, Meller S, Lande R, Kontoyiannis DP, Modlin RL et al. Cytosolic sensing of extracellular self-DNA transported into monocytes by the antimicrobial peptide LL37. Blood 2012; 120: 3699-3707.

37. Canbay A, Feldstein AE, Higuchi H, Werneburg N, Grambihler A, Bronk SF et al. Kupffer cell engulfment of apoptotic bodies stimulates death ligand and cytokine expression. Hepatology 2003; 38: 1188-1198. 